\title{
RURALIDADES NO MUNICÍPIO DE PORTO DA FOLHA/SE: ATIVIDADES NÃO AGRÍCOLAS E DINÂMICAS TERRITORIAIS ${ }^{1}$
}

\author{
José Natan Gonçalves da Silva ${ }^{2}$ \\ Sônia de Souza Mendonça Menezes ${ }^{3}$
}

\section{Resumo}

O processo de desenvolvimento de atividades não agrícolas no campo apresenta-se em expansão e tem impulsionado o surgimento de novas práticas econômicas e a reconfiguração do espaço rural, cenário que reforça a necessidade de releitura acerca da relação campo/cidade, rural/urbano. Diante disso, este artigo tem como objetivo analisar as interfaces das dinâmicas socioeconômicas associadas ao avanço de atividades não agrícolas no espaço rural do município de Porto da Folha/SE. A metodologia baseia-se em revisões da literatura, levantamento de dados estatísticos, pesquisas de campo e aplicação de entrevistas semiestruturadas junto aos agricultores e moradores de comunidades rurais. Evidenciamos a resistência de atividades não agrícolas alicerçadas na dinâmica cultural do território sertanejo, bem como, o crescimento de práticas econômicas comerciais e prestadoras de serviço, até recentemente, restritas ao espaço urbano.

Palvras-chaves: Ruralidades. Atividades não agrícolas. Territorialidades.

\section{RURALITIES IN THE MUNICIPALITY OF PORTO DA FOLHA/SE: NON- AGRICULTURAL ACTIVITIES AND TERRITORIAL DYNAMICS}

\begin{abstract}
The process of development of non-agricultural activities in the field is expanding and has stimulated the emergence of new economic practices and the reconfiguration of the rural space, a scenario that reinforces the nerd to re-read about the field/city, rural/urban. Faced with this, this article aims to analyze the interfaces of the socioeconomic dynamics associated with the progress of non-agricultural activities in the rural area of the municipality of Porto da Folha/SE. The methodology is based on literature reviews, statistical data collection, field surveys and the application of semi-structured interviews with farmers and residents of rural communities. We evidence the resistance of non-agricultural activities based on the cultural
\end{abstract}

\footnotetext{
${ }^{1}$ Este artigo é uma versão atualizada da dissertação de mestrado intitulada: Reconfiguração do espaço rural de Porto da Folha/SE: inovações socioprodutivas e ruralidades, apresentada ao PPGEO/UFS Programa de Pósgraduação em Geografia da Universidade Federal de Sergipe, 2016.

${ }^{2}$ Graduado em Geografia pela Universidade Federal de Sergipe. Mestre em Geografia pelo Programa de Pósgraduação em Geografia da Universidade Federal de Sergipe - PPGEO/UFS. Doutorando em Geografia pelo Programa de Pós-graduação em Geografia da Universidade Federal de Sergipe - PPGEO/UFS. E-mail: natanufs@gmail.com.
}

\footnotetext{
${ }^{3}$ Professora Adjunto do Departamento de Geografia da Universidade Federal de Sergipe, Coordenadora do Programa de Pós- Graduação em Geografia PPGEO/UFS. Doutorado em Geografia -PPGEO/UFS. Líder do GRUPAM- Grupo de Estudos e Pesquisas sobre alimentos e manifestações tradicionais. E-mail: soniamendoncamenezes@gmail.com.
} 
dynamics of the backwoods territory, as well as, the growth of commercial economic practices and service providers, until recently, restricted to the urban space.

Key-words: Ruralities. Non-agricultural activities. Territorialities.

\section{RURALIDADES EN EL MUNICIPIO DE PORTO DA FOLHA/SE: ACTIVIDADES NO AGRÍCOLAS Y DINÁMICAS TERRITORIALES}

\section{Resumen}

El proceso de desarrollo de actividades no agrícolas en el campo se presenta en expansión y ha impulsado el surgimiento de nuevas prácticas económicas y la reconfiguración del espacio rural, escenario que refuerza la necesidad de relectura acerca de la relación campo/ciudad, rural/urbano. Por este motivo, este artículo tiene como objetivo analizar las interfaces de las dinámicas socioeconómicas asociadas al avance de actividades no agrícolas en el espacio rural del municipio de Porto da Folha/SE. La metodología se basa en repasos de la literatura, levantamiento de datos estadísticos, investigaciones de campo y aplicación de entrevistas semiestructuradas junto a los agricultores y moradores de comunidades rurales. Evidenciamos la resistencia de actividades no agrícolas basadas en la dinámica cultural del territorio del sertón, así como, el crecimiento de prácticas económicas comerciales y prestadoras de servicio, hasta recientemente, restringidas al espacio urbano.

Palabras-clave: Ruralidades. Actividades no agrícolas. Territorialidad.

\section{INTRODUÇÃO}

O desenvolvimento de novas práticas econômicas no campo, não raro, dissociadas da agricultura configuram novas ruralidades, que possuem a capacidade de dinamizar e diversificar atividades produtivas do campo, desempenhadas por membros da agricultura familiar e trabalhadores liberais. Tais análises no Brasil partiram das mudanças ocorridas no Sul-Sudeste, predominantemente, baseadas em autores europeus (CHAMBOREDON, 1980; SARACENO, 1996). No Nordeste brasileiro, Wanderley $(2001 ; 2002)$ inicia as discussões sobre essa nova configuração do espaço rural, concebida como estratégia de desenvolvimento territorial e fortalecimento das unidades de produção familiar.

Partindo desta premissa, este artigo tem como objetivo analisar as interfaces das dinâmicas socioeconômicas engendradas pelo crescimento de atividades não agrícolas no espaço rural. O recorte empírico definido para a efetivação da pesquisa foi o município de Porto da Folha/SE, situado na Microrregião Sergipana do Sertão do São Francisco (IBGE).

A metodologia utilizada consistiu em revisões da literatura, levantamento de dados estatísticos, pesquisas de campo e aplicação de entrevistas semiestruturadas. Na ocasião foram 
identificadas previamente 282 unidades de comércio e serviços em 13 comunidades rurais: Lagoa da Volta, Lagoa Redonda, Lagoa do Rancho, Linda França, Ilha do Ouro, Niterói, Mocambo, Ilha de São Pedro, Umbuzeiro do Matuto, Vaca Serrada, Ranchinho, São Domingos e Lagoa do Mato.

Desse quantitativo foram aplicadas 147 entrevistas resultantes de uma amostra fundamentada na metodologia snowball (VINUTO, 2014). A técnica consiste na utilização de informantes-chaves, que indicam a localização de pessoas situadas dentro de uma população geral e com perfil necessário à execução da pesquisa. Em seguida, as pessoas indicadas apontam novos contatos através da sua rede pessoal que, sucessivamente formam cadeias de referência e o quadro de amostragem de interesse do pesquisador. O número de entrevistados dentro do conjunto geral de estabelecimentos identificados, adequou-se aos pressupostos definidos na técnica da "bola de neve", ou seja, a saturação da amostragem ocorreu à medida que os novos nomes indicados não traziam novas informações ao quadro de análise.

Os dados levantados nas entrevistas de campo consistem os principais aportes analíticos da pesquisa, tendo em vista, que os estabelecimentos identificados são classificados como informais e, portanto, não estão inseridos no Cadastro Comercial de Sergipe e são invisíveis pelos órgãos de pesquisa governamentais.

As atividades não agrícolas desenvolvidas nas comunidades rurais suscitam questionamentos sobre a dinâmica da estrutura econômica e cultural do campo, mais especificamente do município de Porto da Folha e do sertão sergipano: as práticas não agrícolas sempre foram desenvolvidas por membros da agricultura familiar? A execução dessas atividades no campo denota a emergência de novos atores no espaço rural, não dedicados exclusivamente a agropecuária? Essas atividades configuram novas ruralidades, ruralidades tradicionais ou ruralidades em processos de ressignificação e reinvenção?

Buscando o aguçamento do debate a partir das questões apontadas, o artigo segue estruturado com a problematização da temática baseada nas relações rural/urbano, ruralidade/urbanidade e campo/cidade. Na sequência são apresentadas as discussões sobre as atividades agroalimentares, comerciais e os serviços no espaço rural do município de Porto da Folha e, por fim, são tecidas as considerações finais. 


\section{REESTRUTURAÇÃO DAS RELAÇÕES PRODUTIVAS NO CAMPO: NOVAS RURALIDADES E ATIVIDADES NÃO AGRÍCOLAS}

A reconfiguração do espaço rural implica no surgimento de diversas concepções sobre as transformações e a revalorização do campo, que dinamizam as unidades de produção familiar. Autores de diferentes áreas do conhecimento, como Graziano da Silva (1981; 1998; 1999a; 1999b), Ianni (1997), Saraceno (1996), Carneiro (1998; 2006), Wanderley (2001; 2002), Moreira (2003), Cavalcanti (2004), Rua (2005; 2006), Abramovay (2009), Schneider (2009), Marafon (2011a; 2011b; 2014) e Saquet (2006; 2014), apesar da diversidade de concepções sobre as transformações do espaço rural brasileiro, asseveram a tendência à reestruturação das relações produtivas e à ressignificação de elementos culturais do campo, atreladas à emergência de novas atividades econômicas, práticas, costumes e valores até recentemente inexistentes no rural, muitos destes outrora limitados aos espaços citadinos.

Nas análises realizadas sobre o rural brasileiro, Graziano da Silva (1981; 1999a; 1999b) toma como base os conceitos rurbano e continuum rural-urbano, demonstrando uma visão unificada do espaço, em que a cidade e o campo viriam a se fundir, compondo uma espacialidade "urbanizada".

A utilização dos conceitos rurbano e continuum rural-urbano são baseados na concepção tradicional europeia. Saraceno (1996) elenca dois problemas atrelados à classificação do rural fundamentada na vertente da urbanização do campo. O primeiro referese à pré-determinação do rural com base na dinâmica demográfica, mais especificamente, associado à condição de vazio demográfico ou reduzido contingente populacional. O segundo concerne à vocação agrícola, indicador ultrapassado ante o processo de modernização da agricultura, que pressionou a população rural a desempenhar atividades não agrícolas (industriais e de serviço) até então incipientes no campo. Contraditoriamente, o rural e o urbano, que apresentam dimensões territoriais, são reduzidos a categorias setoriais: o campo com base na agricultura, e a cidade, referenciada pela indústria e pelos serviços.

Wanderley $(2001$; 2002) realiza uma releitura acerca da vertente da urbanização do rural e defende a tese da existência de semelhanças entre os extremos do continuum ruralurbano, o que não significa a eliminação de particularidades específicas dos dois polos. Apesar da integração e comunicação entre os espaços, esse processo não condiciona o fim da realidade cultural, social e econômica do campo. 
As discussões sobre as transformações do rural realizadas por Rua $(2005 ; 2006)$ reportam para as contradições em torno da política fundiária e agropecuária do Brasil. Influenciado pela dinâmica espacial a qual analisa - o interior fluminense, marcado intensamente pela urbanização - o autor defende a concepção de urbanidades no rural. Na sua análise, o espaço urbano "comanda o processo de reestruturação espacial no mundo contemporâneo" (RUA, 2005, p.57). Entretanto, adverte que não se trata da dissolução do campo pela cidade, mas da coexistência de elementos do campo e da cidade no mesmo espaço. São práticas, atividades, valores, ideias, predominantemente encontradas no espaço urbano que atualmente se deslocam e são protagonizadas no rural (urbanidades no rural), processo impulsionado pela fluidez das fronteiras entre campo/cidade e a interação transescalar entre os territórios no espaço globalizado.

O pensamento de Marafon (2011a; 2011b; 2014) se aproxima da abordagem defendida por Rua $(2005 ; 2006)$. O autor remete a existência da relação dialética entre campo/cidade, rural/urbano e ruralidade/urbanidade. Imbuídas nas relações entre esses pares, encontram-se as trocas e fluxos materiais, imateriais e culturais que requalificam os territórios. Desse modo, "as ruralidades se desenvolvem, também, nos espaços urbanos e as urbanidades podem se desenvolver nos espaços rurais" (MARAFON, 2014, p. 6). A emergência de novas práticas, atividades e técnicas conformam espaços marcados pela diversidade de objetos e relações, alguns inerentes ao território, e outros até recentemente estranhos.

A proposta de urbanidades, na concepção de Candiotto e Corrêa (2008), comporta o pluralismo de ações e objetos urbanos que alteram as representações, a percepção e a identidade da população rural. Destarte, a incorporação no campo de práticas do turismo, veraneio e atividades não agrícolas - relativamente difundidas pela expansão dos meios de comunicação informativos - impulsiona a adesão de novos hábitos nos territórios rurais, confirmando a lógica da expansão das urbanidades no campo.

Ao discutir as concepções de ruralidade e urbanidade, Saquet $(2006$; 2014) emprega a noção de territorialidade. Essas dimensões são "compostas por elementos e processos sociais e territoriais historicamente definidos" (SAQUET, 2014, p. 2). A ruralidade resulta de ações econômicas, sociais e culturais, que se distingue da vida urbana e, portanto, não pode ser entendida como deslocamento do urbano, apesar de se admitir que sua composição é influenciada pelas interações entre o rural e o urbano, o local e o global. Para Saquet (2010), essa complementaridade por mais que exija a requalificação e reconfiguração do território, não o anula. 
Por sua vez, Saraceno (1996), Carneiro (1998), Wanderley (2001; 2002), Moreira (2003) e Cavalcanti (2004), por meio de uma abordagem sociológica e antropológica, defendem os conceitos de ruralidades e novas ruralidades. Trata-se da emergência e reestruturação de práticas, atividades econômicas, relações produtivas, sociais e culturais em decorrência do aguçamento das relações campo/cidade, rural/urbano e local/global, que não exprimem, necessariamente, a sobreposição do urbano em relação ao rural.

Desse modo, considera-se que a emergência de novas práticas no campo não é determinada pela dinâmica eminentemente urbana. Apesar de influenciada pelas urbanidades, as novas ruralidades e as ruralidades tradicionais (legitimadas culturalmente no território) possuem elementos atrelados à conjuntura social, econômica e cultural do campo. Para além da relação urbano/rural, as transformações no campo reforçam as condições de dinamicidade e ressignificação da cultura e práticas socioeconômicas desse espaço.

Para Abramovay (2009), na composição das novas ruralidades está implícito o processo de revalorização do rural. Suas análises afirmam que o campo tem sido marcado pelo avanço de atividades não agrícolas exercidas por moradores rurais, que não necessariamente são agricultores. Pelo contrário, tratam-se cada vez mais de funcionários públicos, profissionais liberais, aposentados, artesãos, guias de turismo e operários. Sendo assim, na medida em que nas "cidades não existem apenas indústrias, no meio rural, tampouco, há só agricultura e agricultores" (ABRAMOVAY, 2009, p. 13). O autor reporta que as novas atividades difundidas no campo dinamizam a conjuntura social e econômica das famílias rurais, configurando elementos inerentes às transformações do território.

Apesar de reconhecerem a importância das atividades não agrícolas no desenvolvimento das atividades produtivas do campo, Candiotto e Corrêa (2008) advertem que a pluriatividade pode fragilizar a agricultura familiar, tendo em vista, que por vezes propicia o desligamento dos agricultores em relação à terra. Diante disso, Schneider (2009) reporta para a diminuição de pessoas ocupadas em postos de trabalho agrícola no espaço rural.

Todavia, mesmo considerando as contradições intrínsecas à expansão das atividades não agrícolas no campo, é relevante a afirmação de Schneider (2009), ao mencionar que a pluriatividade tem contribuído na geração e circulação de renda no campo, não raro, aplicada na manutenção do estabelecimento rural e das atividades agrícolas. Trata-se de estratégias de reprodução social e econômica das famílias rurais, que estimulam a fixação do tecido social no território. Perondi e Schneider (2011) acrescentam que a diversidade em processos sociais 
e econômicos desempenhados pelas famílias pluriativas oportunizam os agricultores a adaptação e a diversificação das práticas produtivas.

Tomando como base as discussões reportadas, a abordagem subsequente traz uma análise da configuração territorial das atividades não agrícolas desempenhados por agricultores familiares e trabalhadores liberais no espaço rural de Porto da Folha.

\section{AS ATIVIDADES AGROALIMENTARES E OS SERVIÇOS NO ESPAÇO RURAL}

As pesquisas efetivadas nas comunidades rurais, além das informações populacionais do município, denotam que viver no campo ainda tem sido uma escolha de diversos grupos sociais: dos 27.146 habitantes de Porto da Folha recenseados pelo IBGE em 2010, 63,33\% residiam no espaço rural e $36,7 \%$, no espaço urbano.

A predominância da população residente no campo também é refletida na composição da estrutura fundiária do município marcada, predominantemente, por minifúndios, pequenos e médios estabelecimentos, mantidos por unidades de produção familiar (Tabela 1).

Tabela 1: Estrutura Fundiária - Porto da Folha/SE - 2006

\begin{tabular}{|c|c|c|c|c|c|c|c|c|}
\hline \multirow{3}{*}{ Grupos de área } & \multicolumn{4}{|c|}{ Unidades da Agricultura familiar } & \multicolumn{4}{|c|}{ Unidades da Agricultura não familiar } \\
\hline & \multicolumn{2}{|c|}{ Estabelecimentos } & \multicolumn{2}{|c|}{ Área } & \multicolumn{2}{|c|}{ Estabelecimentos } & \multicolumn{2}{|c|}{ Área } \\
\hline & Número & $\%$ & ha & $\%$ & Número & $\%$ & ha & $\%$ \\
\hline Total & 2.395 & 100,00 & 48.512 & 100,00 & 116 & 100,00 & 13.480 & 100,00 \\
\hline Menos de 2 ha & 345 & 14,41 & 336 & 0,69 & 7 & 6,03 & 8 & 0,06 \\
\hline 2 a -5 há & 309 & 12,90 & 1.076 & 2,22 & 5 & 4,31 & 14 & 0,10 \\
\hline 5 a -10 há & 541 & 22,59 & 3.989 & 8,22 & 4 & 3,45 & 29 & 0,22 \\
\hline 10 a -20 ha & 538 & 22,46 & 7.723 & 15,92 & 21 & 18,10 & 310 & 2,30 \\
\hline 20 a -50 ha & 475 & 19,83 & 14.516 & 29,92 & 24 & 20,69 & 774 & 5,74 \\
\hline 50 a -100 ha & 127 & 5,30 & 8.935 & 18,42 & 23 & 19,83 & 1.825 & 13,54 \\
\hline 100 ha e mais & 60 & 2,51 & 11.938 & 24,61 & 32 & 27,59 & 10.520 & 78,04 \\
\hline
\end{tabular}

Tanezini (2014) afirma que a estrutura fundiária de Porto da Folha assemelha-se a dos demais municípios que formam o sertão sergipano. Para a autora, a atual configuração do território fundiário decorre do desenvolvimento de políticas de reforma agrária, a partir da década de 1980, que foram materializadas na implementação de projetos de assentamentos rurais e na demarcação territorial de comunidades tradicionais, indígena (Kiriri-Xokó) e quilombolas. Dados disponíveis pelo INCRA apontam que, até o ano de 2015 em Porto da Folha, 251 famílias foram beneficiadas com projetos de assentamentos rurais, que incorporavam uma área total de 5.905 hectares. 
A relevância da população residente no campo também se deve a presença de aglomerados rurais no município. Conforme o IBGE (2010), Porto da Folha possui nove aglomerados rurais ${ }^{4}$ : Lagoa da Volta, Lagoa Redonda, Lagoa do Rancho, Linda França, Ilha do Ouro, Niterói, Mocambo, Ilha de São Pedro e Umbuzeiro do Matuto, que totalizam 8.440 habitantes e 2.365 domicílios.

Santos e Andrade (1992) já haviam retratado em seus estudos sobre o comportamento demográfico em Sergipe que o crescimento da população rural em alguns municípios do estado apresentava especificidades no que diz respeito ao tipo de povoamento. Conforme os autores, "do disperso, partiu-se de forma cada vez mais acentuada, para um povoamento rural aglomerado" (SANTOS; ANDRADE, 1992, p. 45). Essa realidade foi constatada em povoados rurais, vilas e pequenas cidades, que apresentaram crescimento considerável, mas, não desempenhavam o papel de áreas urbanas.

Em Porto da Folha, os aglomerados rurais foram formados historicamente com o estabelecimento da pecuária extensiva, aliada a constituição de núcleos rurais, onde são desenvolvidas atividades não agrícolas associadas às práticas comerciais, de serviços e à produção agroalimentar artesanal de derivados de leite (MENEZES, 2009; MENEZES; CRUZ, 2017).

A execução de atividades não agrícolas no campo comporta-se como prática recorrente entre agricultores e trabalhadores liberais que vivem no espaço rural do município. Diante desse contexto, torna-se relevante a afirmação de Wanderley (2001), ao mencionar que a pluriatividade não raro tem sua origem nas unidades de produção familiar.

Constatou-se nas pesquisas que, até recentemente muitas atividades não agrícolas estavam limitadas ao espaço urbano. Todavia, na sua expansão para o campo, essas adquirem especificidades atreladas à dinâmica cultural, econômica, ambiental e ecológica do espaço rural, o que não exclui a manutenção de elementos eminentemente urbanos.

Vê-se, portanto, entre o rural e o urbano, entre o local e o global, o processo dinâmico de reelaboração da cultura, por meio do compartilhamento e imposição de novos hábitos, valores e técnicas (CARNEIRO, 1998). Para Carneiro (1998), Wanderley (2001) e Moreira (2003), esse processo alude para emergência e ressignificação de atividades no campo, que

\footnotetext{
${ }^{4} \mathrm{Na}$ metodologia de pesquisa utilizada pelo IBGE, as comunidades que têm 50 ou mais domicílios contíguos são classificadas como aglomerados rurais. As demais localidades são consideradas de povoamento disperso e não são contempladas com o recenseamento específico do núcleo rural.
} 
reforçam o conceito das novas ruralidades, ou seja, novas manifestações que aguçam a dinamicidade social, econômica e cultural do rural.

Os estudos realizados por Wanderley $(2001 ; 2002)$ na região Nordeste apontam o avanço de atividades não agrícolas no campo. A contribuição da autora é ímpar, diante das demais referências, cujo contexto empírico reporta às regiões Sul e Sudeste do Brasil. Essas pesquisas assinalam que as novas práticas produtivas do campo - as quais conferem aos agricultores a condição de pluriativos - trazem intrinsecamente elementos do rural, como a paisagem bucólica, o ar puro, a tranquilidade e bens ecológicos e culturais, destinados aos urbanitas, que fogem de uma realidade metropolitana marcada pela contração do tempo, artificialidade, stress, violência, insegurança, poluição, dentre outros elementos característicos dos centros urbanos.

Nos estudos realizados no norte do estado do Rio de Janeiro (RUA, 2005; 2006; MARAFON, 2011a; 2011b; 2014) e no Circuito Italiano do município de Colombo/PR (CANDIOTTO; CORRÊA, 2008), sobressai a oferta de serviços associados ao lazer, como hotéis-fazenda, pousadas, spas e restaurantes, articulada a roteiros turísticos que exploram o patrimônio natural e cultural preservados por membros da agricultura familiar, além de atividades de comercialização e consumo de produtos agroecológicos e artesanais.

Nesse contexto, Beber e Menasche (2015), reportam para a experiência turística atrelada à partilha da vida cotidiana na Fazenda do Amor, propriedade rural situada nos Campos de Cima da Serra, no estado do Rio Grande do Sul. Dentre as atividades, destacam-se o consumo e o vislumbre dos turistas pelos hábitos da fazenda, a estrutura da casa e os objetos imbricados de história e cultura pertencentes a esse território. Para tanto, o espaço doméstico e a rotina familiar é regulado por processos operacionais ligados aos serviços de turismo. Nota-se que a natureza, as tradições e os hábitos rurais passam a ser concebidos pela população urbana como mercadorias ofertadas pelo homem do campo.

Todavia, o rural brasileiro é diversificado e complexo devido as diferentes formas de ocupação e desenvolvimento das práticas econômicas, não podendo ser concebido como alvo de processo idêntico de transformação. A dinâmica apresentada anteriormente distingue de características observadas no espaço rural de Porto da Folha, sobretudo no tocante às atividades desenvolvidas e aos atores que usufruem os serviços ofertados.

Diferentemente dos estudos realizados no eixo Sul-Sudeste do Brasil, as atividades desenvolvidas no município, majoritariamente não possuem relação com o turismo, nem tampouco estão direcionadas exclusivamente para os urbanitas. No recorte empírico 
analisado, predominam atividades comerciais e de serviços direcionadas, principalmente à população rural constituída por agricultores e trabalhadores liberais residentes no campo.

Os 147 estabelecimentos alvos das entrevistas são responsáveis pela geração de 361 postos de trabalho nas comunidades rurais. Dessas ocupações, 85,04\% são executadas por pequenos empreendedores e membros de suas famílias, enquanto $14,96 \%$ postos são ocupados por trabalhadores que não possuem origem familiar com os proprietários dos estabelecimentos comerciais e de serviços. Esse cenário reflete a relevância das famílias rurais no encadeamento das atividades não agrícolas, bem como, o protagonismo de atores locais que compõem a estrutura de pequenos empreendedores rurais.

Nota-se ainda entre os comerciantes e os profissionais o predomínio da relação familiar com a agricultura. Foi constatado na pesquisa que 96,60\% dos entrevistados descendem de famílias de agricultores, enquanto apenas 3,40\% não possuem nenhuma relação com as atividades agrícolas (Gráfico 1). Quando analisado o número de comerciantes que afirmaram possuir relação familiar com as atividades agrícolas, observa-se que 55,63\% mencionaram não estar vinculados a agricultura (Gráfico 2).

Gráfico 1: Porto da Folha/SE Familiaridade dos Comerciantes com as Atividades Agrícolas - 2016

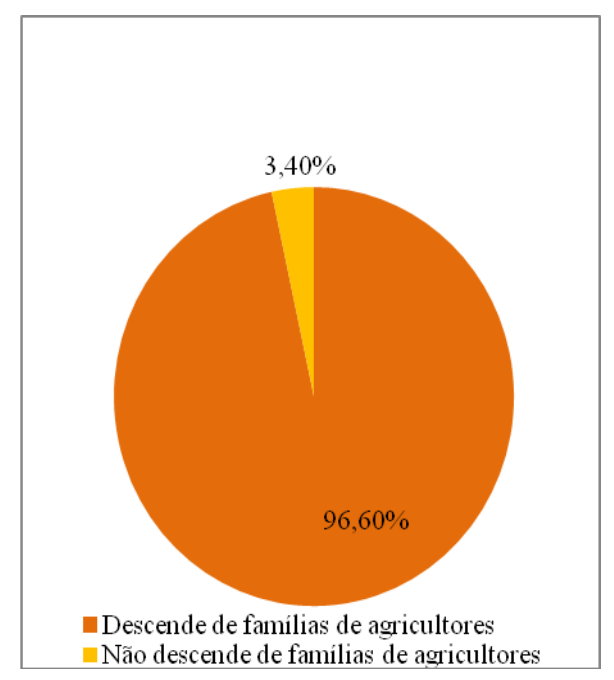

Fonte: Pesquisa de campo, 2016.
Gráfico 2: Porto da Folha/SE Relação dos Comerciantes com as Atividades Agrícolas - 2016

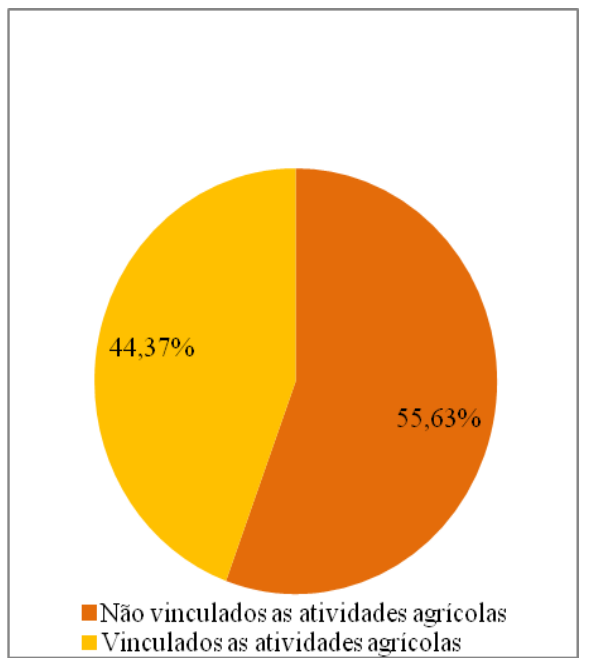

Fonte: Pesquisa de campo, 2016. 
Com base nos relatos dos entrevistados, apesar do reconhecimento da melhoria de vida dos agricultores locais devido às políticas de transferência de renda, financiamento agrícola e seguridade social, os fatores que motivaram a adesão exclusiva às atividades não agrícolas foram a busca por novas alternativas de sobrevivência, diante dos entraves periódicos com a agropecuária motivados pelos efeitos das estiagens prolongadas, recorrentes no sertão sergipano. Além disso, eles reforçam que o crescimento das comunidades e as exigências por novos serviços pela população rural os instigaram a desenvolver atividades vinculadas ao comércio e à prestação de serviços.

Verificou-se ainda que $44,37 \%$ dos comerciantes continuam exercendo atividade agrícola (Gráfico 2). Para eles a manutenção das duas atividades é fundamental na elevação da renda familiar e comportam-se como complementares. Trabalhar na terra é também preservar um modo de vida que atribui significado à sua existência e legitima sua história e de seus antepassados. Para tanto, o rural não deve ser percebido apenas como um espaço onde se concretizam as práticas produtivistas, mas, como evidencia Woortmann (1995), também precisa ser visualizado como um meio carregado de valores, que expressa um modo de vida. Nesse ínterim, é relevante o pensamento de Candiotto e Corrêa (2008), ao reportarem que a manutenção das atividades agrícolas e não agrícolas consistem territorialidades protagonizadas por atores originários do rural, que buscam permanecer no campo.

No tocante às perspectivas dos comerciantes sobre as atividades que desenvolvem, eles acreditam na possibilidade de fortalecimento das práticas não agrícolas. Para além da importância dessas atividades na reprodução da família, viver e usufruir de elementos característicos do rural, como a tranquilidade, o ar puro e a convivência entre amigos e familiares, os motivam na busca por alternativas de manutenção da atividade econômica com a finalidade de continuar no campo, mesmo que o contexto financeiro por vezes não se apresente promissor.

Desse modo, também é relevante o pensamento de Carneiro (2006) ao reforçar que o campo nunca foi exclusivamente agrícola. Segundo a autora, a realização de atividades não agrícolas sempre consistiu a essência da agricultura de base familiar e, por sua vez, não foi eliminada integralmente da unidade de produção. $\mathrm{O}$ que difere da atual estrutura das famílias rurais é o fato da execução dessas novas práticas, por vezes, refletir a crise e a perda da autonomia das unidades de produção familiar frente às condições de subalternidade a qual estão sujeitas ante o avanço das relações de produção capitalista no campo. 
No espaço rural do município, as atividades não agrícolas sempre foram protagonizadas pelas famílias rurais, juntamente com a agricultura e a pecuária, configurando ruralidades tradicionais por remeterem, ainda que ressignificadas, a uma referência cultural do território. Nesse interim, sobressai a produção agroalimentar dos derivados de leite que, consolidou-se ao longo de diferentes temporalidades como atividade não agrícola desenvolvida paralela às práticas do pastoreio bovino.

Menezes (2015a) retrata que no sertão sergipano o avanço gradativo das pastagens decorre dos incentivos de programas e projetos públicos direcionados à pecuária leiteira a partir da década de 1980. Os estímulos ao desenvolvimento da pecuária adequaram-se à configuração econômica do semiárido e ao perfil sociocultural do sertanejo, historicamente responsável pelo povoamento dos sertões através da criação extensiva de gado. Após os incentivos a bovinocultura, o leite ordenhado em pequenos, médios e grandes estabelecimentos constitui produto comercial direcionado aos laticínios, fabriquetas de queijos ou unidades de produção caseira responsáveis pela elaboração do queijo coalho artesanal. Enquanto nas indústrias e fabriquetas são criados postos de trabalho para profissionais como transportadores de leite, queijeiros, comerciantes de queijo, nas unidades caseiras são consolidados ofícios e saberes das mulheres sertanejas que realizam a elaboração artesanal do queijo coalho.

Como asseveram Menezes e Cruz (2017, p. 28) a produção e o consumo de alimentos, arraigados aos locais de origem, "fortalecem dinâmicas territoriais, uma vez que, ao proporcionar interação entre os territórios e os produtos, promovem inovações nos alimentos e, ainda, envolvem distintos atores sociais". A abordagem das autoras foi constatada no espaço rural do município, sobretudo na produção dos derivados do leite, no qual se observa a tradição associada à elaboração artesanal e a comensalidade dos produtos, paralela à ressignificação de práticas observadas na padronização de técnicas, aquisição de maquinários industriais (desnatadeiras, embaladoras a vácuo, fornos elétricos, tanques e câmaras de resfriamento) e no estreitamento das relações de produção e consumo, identificado na embalagem do requeijão e da manteiga em tamanhos e porções variadas, para atender os perfis dos diferentes consumidores, bem como, no uso de selos e rótulos, que associam os produtos aos aspectos bucólico, natural, artesanal e caseiro da fazenda e da roça.

No tocante as atividades não agrícolas tradicionais eram relevantes no município à produção agroalimentar dos derivados da mandioca: farinha, tapioca, massa pubá, beijú, pé- 
de-moleque, mal casado e saquarema (bolachas de goma). Esses alimentos, além de estarem inseridos na cultura alimentar do sertanejo, possuíam valor de troca e eram convertidos em produtos comerciais nas feiras-livres. Todavia, a decadência da produção de mandioca, apontada por Menezes (2015b) como consequência do avanço de pastagens no sertão sergipano, fragilizou as atividades das chamadas casas de farinha, espaços de trabalho coletivo alicerçados nas relações de sociabilidade, proximidade e pautados na difusão de saberes/fazeres associados à elaboração das iguarias e quitutes.

Referente às atividades não agrícolas tradicionais também vale destacar profissões e ofícios que foram extintos, ou passam por processos de eliminação. Dentre essas se destacam a extinção do ferreiro, demandado na produção de ferramentas a partir da fundição do metal; do caixeiro viajante, substituído pelos representantes comerciais; do construtor dos cercados de pedra, atualmente erguidos com estacas de madeira, de cimento e arame farpado.

Configuram-se ainda em profissões e estabelecimentos comerciais sujeitos à eliminação: o marceneiro, que perde espaço diante do crescimento da indústria e do comércio mobiliário; os botecos, onde eram servidas as tradicionais cachaças e pingas incrementadas com as denominadas cascas de pau e folhagens retiradas da vegetação da caatinga, que hoje cedem espaço para bares tomados pelo marketing das cervejarias; e as bodegas, com seu típico balcão de madeira, que separava o espaço do cliente e do comerciante responsável pela entrega dos produtos diretamente ao consumidor. Atualmente esses estabelecimentos são substituídos por minimercados marcados pela diversidade de produtos e pela diminuta relação entre o cliente e o comerciante no processo de compra e venda.

Em contrapartida, verifica-se que antigos ofícios e estabelecimentos tradicionais ainda resistem, mesmo que apresentem mudanças e ressignificações: o serralheiro, profissional demandado na construção artesanal de porteiras, mourões, carroças e carros de boi; a barbearia, que persiste como ponto de encontro entre amigos e espaço de sociabilidade, mesmo com a expansão dos salões de beleza e da indústria cosmética; o carpinteiro, exigido principalmente na construção da estrutura dos telhados dos domicílios; o carreiro, com seus carros de bois, demandado no transporte de insumos agrícolas e materiais da construção civil; o marchante, responsável pelo abate dos animais (bovinos, suínos, caprinos e ovinos) e comercialização de carnes nas feiras-livres; e os canoeiros, que diariamente realizam a travessia de pessoas nas águas do rio São Francisco.

Também resiste o ofício de corte e costura, no qual mulheres expõem seus saberes herdados de suas mães e avós, mesmo que adiram a máquinas industriais e aos novos estilos 
de confecção; as bordadeiras e as rendeiras, que preservam a arte dos bordados de crochês e ponto de cruz; e os feirantes, ocupação tradicionalmente difundida no Nordeste do Brasil (BRUNETT, 2017). Em Porto da Folha, a principal feira-livre é realizada às segundas-feiras no espaço urbano, mas a partir de 2017, esses espaços que conjugam relações comerciais, de lazer, sociabilidade e proximidade foram resgatados e difundidos em aglomerados rurais do município, como estratégia de geração de postos de trabalho, dinamização das atividades comerciais e criação de mercados alternativos à comercialização de produtos agroecológicos.

Percebe-se ainda que muitas práticas econômicas prestadoras de serviços atualmente reproduzidas no território constituem novas ruralidades. Trata-se de setores totalmente reinventados ou até recentemente inexistentes no campo, resultantes das exigências de segmentos da população rural diante dos processos de ascensão social e econômica e devido à influência da cultura mercantilizada. Destacam-se dentre essas atividades e profissionais: o pedreiro, o taxista, o caminhoneiro, o tratorista, a manicure e pedicure, o atendente de loja, os servidores públicos municipais e estaduais (professores, merendeiras, serventes, vigilantes) e à expressiva diversidade de estabelecimentos comerciais.

Conforme apresentado na tabela 2 , dentre os estabelecimentos identificados predominam aqueles voltados para a comercialização de alimentos e bens domésticos não duráveis (45 minimercados e mercearias). O fator que contribuiu para a expansão dessa atividade no espaço rural foram as políticas de transferência de renda do governo federal, especialmente o Programa Bolsa Família. Dados do Ministério do Desenvolvimento Social (MDS) apontam que 2.959 famílias eram beneficiadas por esse programa no ano 2004. Já no mês de referência de dezembro de 2018, os números de beneficiários correspondiam a 5.474 famílias (BRASIL, 2018).

O benefício destinado, principalmente às mulheres é utilizado, majoritariamente na obtenção de alimentos, contribuindo para o crescimento dos setores de comercialização desses produtos alimentícios. Considerando os impactos gerados pelo programa no espaço rural do Brasil, Silva e Schneider (2015) reportam sobre sua importância na elevação da renda e nos ganhos alimentares e nutritivos das famílias. Na perspectiva dos autores, tais fatores contribuíram na redução da desigualdade social e da pobreza e extrema pobreza no campo. 
Tabela 2: Estabelecimentos Comerciais e Prestadores de Serviços no Espaço Rural Porto da Folha/SE - 2016

\begin{tabular}{|c|c|c|}
\hline Tipo de Estabelecimento & Número & $\%$ \\
\hline Minimercado/Mercearia & 45 & 15,96 \\
\hline Bares & 43 & 15,24 \\
\hline Oficina de Motocicleta & 22 & 7,80 \\
\hline Lanchonetes & 19 & 6,74 \\
\hline Lojas de Decoração & 15 & 5,32 \\
\hline Restaurantes & 13 & 4,61 \\
\hline Borracharias & 11 & 3,91 \\
\hline Barbearias & 10 & 3,55 \\
\hline Padarias & 10 & 3,55 \\
\hline Vestuário & 9 & 3,19 \\
\hline Salão de Beleza & 8 & 2,84 \\
\hline Insumos Agrícolas & 7 & 2,48 \\
\hline Farmácias & 6 & 2,13 \\
\hline Material de Construção & 6 & 2,13 \\
\hline Frigoríficos & 6 & 2,13 \\
\hline Distribuidora de Bebidas & 5 & 1,77 \\
\hline Sorveterias e Ponto de Açaí & 5 & 1,77 \\
\hline $\begin{array}{l}\text { Jogos eletrônicos/Vídeo } \\
\text { Game }\end{array}$ & 4 & 1,42 \\
\hline Lava Jato & 4 & 1,42 \\
\hline Corte e Costura & 4 & 1,42 \\
\hline Academias & 4 & 1,42 \\
\hline Serrarias & 3 & 1,06 \\
\hline Docerias & 3 & 1,06 \\
\hline Esquadrilha de Aço & 3 & 1,06 \\
\hline Balneários & 3 & 1,06 \\
\hline Distribuidora de Botijão & 2 & 0,71 \\
\hline Pousadas & 2 & 0,71 \\
\hline Ponto Bancário & 2 & 0,71 \\
\hline Eletrônicas & 2 & 0,71 \\
\hline Móveis Domésticos & 2 & 0,71 \\
\hline Reforço Escolar & 2 & 0,71 \\
\hline Escola privada & 1 & 0,35 \\
\hline Madeireira & 1 & 0,35 \\
\hline Total & 282 & 100 \\
\hline
\end{tabular}

Fonte: Pesquisa de campo, 2016.

Org. GONÇALVES DA SILVA, J. N. MENEZES, S. S. M. 2016.

Os minimercados e mercearias praticamente não apresentam nenhuma relação com os antigos armazéns e bodegas, cujas principais características são o balcão de madeira, onde o proprietário realizava o atendimento aos clientes, e os reduzidos tipos de produtos, muitos desses pesados e ensacados pelo próprio comerciante. Notaram-se ainda inúmeros produtos de 
variadas marcas de empresas nacionais e multinacionais que já aderem à lógica mercantilizada do marketing.

Outra mudança expressiva nas comunidades diz respeito ao crescimento de borracharias e oficinas mecânicas especializadas na manutenção de veículos. O que contribuiu para esse contexto foi o aumento da aquisição de meios de transportes mecânicos pela população local: motocicleta, automóvel, caminhão e trator, bem como, a utilização desses veículos nas atividades agropecuárias. Nas comunidades pesquisadas foram identificadas 22 oficinas de motocicletas e 11 borracharias.

Atrelado ainda à dinâmica do espaço rural e às transformações das atividades agropecuárias, observa-se nos aglomerados rurais e cidades circunvizinhas a especialização de estabelecimentos na comercialização de insumos agrícolas: milho (transgênico e convencional), farelo, soja, ração, pulverizadores, semeadeiras manuais, além de utensílios empregados na manutenção dos estabelecimentos rurais e nas atividades realizadas pelos agricultores: arame farpado, cordas, baldes, botas e chapéus.

Percebe-se ainda a estruturação de estabelecimentos de vestuário, decoração, salão de beleza, sorveteria, lanchonete, bares e academia. Esse último reflete a adoção de novos costumes e preocupações com o corpo e a saúde. Trata-se de novos valores influenciados pelos discursos midiáticos e da cultura de massas. Muitos dos produtos não consistem em bens de consumo básico, contudo, sua oferta é indicativo do aumento da capacidade de consumo dos atores locais.

O crescimento populacional dos povoados, a estruturação de áreas de comércio e a ampliação de serviços básicos, como saúde, transporte e educação, impulsionou a criação de restaurantes e pousadas destinadas ao atendimento de visitantes, trabalhadores liberais e funcionários públicos que residem em outras localidades e realizam migrações pendulares ou temporárias (semanais) para as comunidades rurais.

Destacam-se ainda os balneários, procurados tanto por visitantes, quanto pelos moradores locais. Diante da ausência de espaços de recreação no espaço rural, esses estabelecimentos constituem atrativos de lazer para a juventude residente no campo e, inclusive, populares provenientes dos municípios e das comunidades circunvizinhas. $\mathrm{Na}$ última década, três balneários foram construídos no espaço rural do município e oferecem as atividades de bar, restaurante, shows musicais, salão de festa e banho de piscina. Além disso, um deles possui campo society e serviços de pernoite e estadias a partir de uma pousada. 
Enquanto isso, no povoado Ilha do Ouro, localizado às margens do rio São Francisco, desenvolvem-se atividades vinculadas a espaços de visitação e exploração de bens ecológicos. No local, os consumidores usufruem das águas do rio para o banho e passeios em lanchas, além dos serviços de bares e restaurantes que servem comidas típicas atreladas à culinária ribeirinha: pirão de peixe, pitú, camarão e peixes assados ou regados ao leite de coco.

Alguns estabelecimentos adaptaram as relações de compra e venda ao pagamento eletrônico diante da facilidade de acesso dos consumidores aos cartões de crédito. Inserem-se nessa nova dinâmica os estabelecimentos destinados aos visitantes e algumas atividades comerciais e prestadoras de serviços usufruídas pelos atores locais, a exemplo das lojas de vestuário, decoração e estabelecimentos agropecuários e de materiais de construção.

Essa nova forma de obtenção de bens e serviços não inviabilizou ou extinguiu as formas de pagamento pautadas nas relações de confiança. Pelo contrário, são essas que mais estimulam as trocas comerciais no espaço rural. O pagamento eletrônico coexiste com antigas práticas, como o fiado e as anotações na caderneta, alicerçadas no pagamento semanal realizado por agricultores e trabalhadores liberais, que recebem nos finais de semana o rendimento auferido de suas atividades informais ou empregatícias.

As relações de confiabilidade e reciprocidade são intrínsecas ao território e permeiam as práticas sociais e, inclusive, as atividades econômicas. Sabourin (2006), ao discutir sobre a influência dos valores humanos na composição das práticas sociais e econômicas, ressalta que nas sociedades rurais atuais persistem estruturas comerciais fundamentadas nas relações de confiança, honestidade e respeito. Percebe-se que mesmo diante das transformações, ruralidades tradicionais atreladas aos valores humanos resistem e influenciam a dinâmica das atividades econômicas no município de Porto da Folha.

Tal fato já havia sido identificado por Menezes (2009) e Menezes e Cruz (2017), ao analisarem as relações comerciais entre produtores e consumidores de produtos agroalimentares artesanais semielaborados no sertão sergipano. Para a autora, nos territórios sertanejos de Sergipe estão imbricadas relações de trocas comerciais pautadas na manutenção das redes de proximidade e sociabilidade, que se confundem com espaços de convivência, amizade e parentesco inerentes à dinâmica do lugar e do cotidiano.

Logo, apesar do avanço das relações de produção capitalista e da racionalização das atividades econômicas, determinadas práticas produtivas desenvolvidas no espaço rural, ainda preservam mercados socialmente constituídos e legitimados por práticas e valores humanos enraizados no território. 


\section{CONSIDERAÇÕES FINAIS}

A reconfiguração do campo decorrente do avanço de atividades não agrícolas implica na necessidade de revisão do conceito de rural, contraditoriamente, associado ao exclusivo desenvolvimento setorial da agricultura, da pecuária e do extrativismo.

Nas análises acerca da dinâmica do espaço rural é preciso atentar-se a multifuncionalidade da agricultura familiar e as diferentes territorialidades desempenhadas pelos agricultores e trabalhadores liberais com a finalidade de permanecerem no campo. Constatou-se que esses sujeitos constituem agentes ativos na definição de estratégias de reprodução socioeconômica, pautadas na execução das atividades agrícolas e não agrícolas, que contribuem para a manutenção do tecido social rural.

Apesar do distanciamento de determinados trabalhadores rurais da agricultura, motivado pela redução dos postos de trabalho agrícola, as pesquisas in loco apontam a possibilidade de complementaridade entre as práticas da agropecuária e aquelas associadas aos setores agroalimentar, de comércio e serviços. A coexistência dessas atividades contribui para a seguridade social e econômica de homens e mulheres que residem no campo.

A resistência de práticas econômicas não agrícolas, culturalmente alicerçadas no território, fundamenta o pensamento de que o campo, mesmo em períodos longínquos, nunca foi eminentemente agrícola. Destarte, é pertinente destacar a relevância das atividades agroalimentares da produção artesanal e semi-industrial de derivados de leite (requeijão, manteiga e queijo coalho), que despontam como alternativas de reprodução social e cultural das famílias rurais.

As atividades não agrícolas, imbrincadas na concepção de ruralidades, exprimem práticas culturais produtivas associadas eminentemente à dinâmica do campo, bem como, novos conteúdos originários de setores econômicos, a priori, limitados ao espaço urbano. Essas atividades, quando expandidas para o campo, não raro são ressignificadas, reinventadas e adaptadas à conjuntura social e econômica dos territórios rurais.

\section{REFERÊNCIAS BIBLIOGRÁFICAS}

ABRAMOVAY, Ricardo. O futuro das regiões rurais. 2. ed. Porto Alegre: Editora da UFRGS, 2009. 
BEBER, Ana Maria Costa; MENASCHE, Renata. "O turismo na pousada Fazenda do Amor e as transformações nos modos de vida". Revista SODEBRAS, Florianópolis/SC, v. 10, n. 114, p. 58-62, jun. 2015.

BRASIL. Ministério do Desenvolvimento Social: Programa Bolsa Família. Disponível: <http://mds.gov.br/assuntos/bolsa-familia>. Acesso: 14 dez. 2018.

BURNETT, Annahid. "Vozes da sulanca: a história oral sobre a instituição da Feira da Sulanca no agreste de Pernambuco". Oralidades, São Paulo, v. 6, n. 11, p. 117-132, jul. 2012.

CANDIOTTO, Luciano Zanetti Pessoa; CORRÊA, Walquíria Kruger. "Ruralidades e urbanidades no circuito italiano de turismo rural, município de Colombo-PR". In: MARAFON, Gláucio José; PESSÔA, Vera Lúcia Salazar (Orgs.). Agricultura, desenvolvimento e transformações socioespaciais. Uberlândia: Assis, 2008. p. 213-249.

CARNEIRO, Maria José. “Ruralidade: novas identidades em construção”. Estudos Sociedade e Agricultura, Rio de Janeiro, n.11, p.53-75, out. 1998.

CARNEIRO, Maria José. "Pluriatividade da agricultura no Brasil: uma reflexão crítica". In: SCHNEIDER, Sérgio (Org.). A diversidade da agricultura familiar. Porto Alegre: UFRGS, 2006. p. 165-185.

CAVALCANTI, Josefa Salete Barbosa. "Globalização e ruralidade”. In: WANDERLEY, Maria de Nazareth Baudel (Org.). Globalização e desenvolvimento sustentável: dinâmicas sociais rurais no Nordeste brasileiro. Campinas/SP: Ceres, 2004. p. 17-32.

CHAMBOREDON, Jean-Claude. "Les usages urbains de l' espace rural: du moyen de production au lieu de récréation”. Revue française de sociologie, Paris, n. 21, v.1, p.97-119, jan-mar. 1980.

GRAZIANO DA SILVA, José. Progresso técnico e relações de trabalho na agricultura. São Paulo: Hucitec, 1981.

GRAZIANO DA SILVA, José. A nova dinâmica da agricultura brasileira. 2. ed. Campinas/SP: UNICAMP, 1998.

GRAZIANO DA SILVA, José. Tecnologia e Agricultura Familiar. Porto Alegre: Ed. UFRGS, 1999a.

GRAZIANO DA SILVA, José. O novo rural brasileiro. Campinas/SP: UNICAMP, 1999b.

IANNI, Octavio. A era do globalismo. 3 ed. Rio de Janeiro: Civilização Brasileira, 1997.

IBGE. População e Estrutura Fundiária de Porto da Folha/SE. Disponível em: <www.ibge.gov.br>. Acesso em: 08 set. 2016.

INCRA. Projetos de Reforma Agrária. Disponível: <www.incra.gov.br〉. Acesso: 23 dez. 2016. 
MARAFON, Glaúcio José. "Principais transformações em curso no espaço rural na atualidade". Revista Geográfica de América Central, Costa Rica, Número Especial, p.6984, 2011a.

MARAFON, Glaúcio José. "Relações campo-cidade: uma leitura a partir do espaço rural fluminense". In: SAQUET, Marcos Aurélio; SUZUKI, Júlio César; MARAFON, Glaúcio José (Orgs.). Territorialidades e diversidade nos campos e nas cidades latino-americanas e francesas. São Paulo: Outras Expressões, 2011b. p. 155-167.

MARAFON, Glaúcio José. "Territorialidades, ruralidades e as relações campo-cidade". Campo-território: Revista de Geografia Agrária. Edição especial do XXI ENGA-2012, Uberlândia/MG, p. 1-13, jun. 2014.

MENEZES, Sônia de Souza Mendonça. A força dos laços de proximidade na tradição e inovação no/do território sergipano das fabriquetas de queijo. 2009. 359f. Tese (Doutorado em Geografia) - Programa de Pós-graduação em Geografia, UFS, São Cristóvão/SE.

MENEZES, Sônia de Souza Mendonça. Queijo artesanal Configurações territoriais: Experiências Escalares do Global ao Local (O caso de Sergipe). São Cristóvão: Editora da UFS, 2015a.

MENEZES, Sônia de Souza Mendonça. "Sabores do Sertão ao Litoral: saberes e fazeres como estratégia de reprodução social e econômica de grupos familiares". Geografias, Belo Horizonte/MG, v. 11, n. 2, p. 44-62, jul.- dez. 2015 b.

MENEZES, Sônia de Souza Mendonça; CRUZ, Fabiana Thomé da. "Alimentos tradicionais como manifestação cultural na contemporaneidade". In: MENEZES, Sônia de Souza Mendonça; CRUZ, Fabiana Thomé da (Orgs.). Estreitando o diálogo entre alimentos, tradição, cultura e consumo. São Cristóvão: Editora da UFS, 2017. p. 25-44.

MOREIRA, Roberto José. "Cultura, política e o mundo rural na contemporaneidade". Estudos Sociedade e Agricultura, Rio de Janeiro, v.11, n. 20, p. 113-143, abr. 2003.

PERONDI, Miguel Angelo; SCHNEIDER, Sergio. "Diversificação agrícola e não agrícola da agricultura familiar". In: SCHNEIDER, Sergio; GAZOLLA, Marcio (Orgs.). Os atores do desenvolvimento rural: perspectivas teóricas e práticas sociais. Porto Alegre: Editora da UFRGS, 2011. p. 205-219.

RUA, João. "A ressignificação do rural e as relações cidade campo: uma contribuição geográfica”. Revista da ANPEGE, Fortaleza/CE, v. 2, n. 2, p. 45-66, ago. 2005.

RUA, João. "Urbanidades no rural: o devir de novas territorialidades. Campo-território: Revista de Geografia Agrária, Uberlândia/MG, v. 1, n. 1, p. 82-106, fev. 2006. Disponível: <http://www.seer.ufu.br/index.php/campoterritorio/article/view/11781/6895>. Acesso: 28 mar. 2017. 
SABOURIN, Eric Pierre. "Práticas sociais, políticas públicas e valores humanos". In:

SCHNEIDER, Sérgio (Org.). A diversidade agricultura familiar. Porto Alegre: Editora da UFRGS, 2006. p. 215-239.

SANTOS, Adelci Figueiredo; ANDRADE, José Augusto. Delimitação e regionalização do Brasil semi-árido - Sergipe. Aracaju: UFS, 1992.

SARACENO, Elena. $O$ conceito de ruralidade: problemas de definição em escala europeia. Tradução: Ângela Kageyama. Programa de Seminários INEA sobre desenvolvimento nas áreas rurais: métodos de análise e políticas de intervenção. Roma, p. 1-9, out. 1996.

SAQUET, Marcos Aurélio. "Por uma abordagem territorial das relações urbano-rurais no Sudoeste paranaense". In: SPOSITO, Maria Encarnação Beltrão; WHITACKER, Arthur Magon. (Orgs.). Cidade e campo: relações e contradições entre urbano e rural. São Paulo: Expressão Popular, 2006. p. 157-186.

SAQUET, Marcos Aurélio. Abordagens e concepções de território. 2. ed. São Paulo: Expressão Popular, 2010.

SAQUET, Marcos Aurélio. “Territorialidades, relações campo-cidade e ruralidades em processos de transformação territorial e autonomia". Campo-território: Revista de Geografia Agrária, Uberlândia/MG, Edição especial do XXI ENGA-2012, p. 1-30, jun. 2014. Disponível: <http://www.seer.ufu.br/index.php/campoterritorio/article/view/26896/14606>. Acesso: 27 jul. 2017.

SCHNEIDER, Sérgio. A pluriatividade na agricultura familiar. 2. ed. Porto Alegre: Editora da UFRGS, 2009.

SILVA, Carolina Braz de Castilho; SCHNEIDER, Sergio. "Pobreza rural e o Programa Bolsa Família - desafios para o desenvolvimento rural no Brasil”. In: GRISA, Catia; SCHNEIDER, Sergio (Orgs.). Políticas públicas de desenvolvimento rural no Brasil. Porto Alegre: Editora da UFRGS, 2015. p. 443-463.

TANEZINI, Theresa Cristina Zavaris. Territórios em Conflitos no Alto Sertão Sergipano. 2014. Tese (Doutorado em Geografia) - Programa de Pós-graduação em Geografia, Universidade Federal de Sergipe, São Cristóvão/SE.

VINUTO, Juliana. "A amostragem em bola de neve na pesquisa qualitativa: um debate em aberto”. Temáticas, Campinas/SP, v. 22, n. 44, p. 203-220, ago/dez. 2014.

WANDERLEY, Maria de Nazareth Baudel. "A ruralidade no Brasil moderno. Por um pacto social pelo desenvolvimento rural”. In: Consejo Latinoamericano de Ciencias Sociales, Ciudad Autónoma de Buenos Aires, 2005, Buenos Aires. Anais de artigos, Buenos Aires/ARG: CLACSO, 2001, p.31-44.

WANDERLEY, Maria de Nazareth Baudel. "Territorialidade e ruralidade no Nordeste: por um pacto social pelo desenvolvimento rural". In: SABOURIN, Eric Pierre; TEIXEIRA, 
Olivio Alberto. Planejamento e desenvolvimento dos territórios rurais. Brasília: EMBRAPA, 2002. p. 39-52.

WOORTMANN, Ellen Fensterseifer. Herdeiros, parentes e compadres. São Paulo: Brasília: Hucitec/EDUNB, 1995.

Recebido em Agosto de 2018

Aprovado em Dezembro de 2018

Publicado em Fevereiro de 2019 